\title{
Quantitative contribution of climate change and human activities to runoff changes in the Wei River basin, China
}

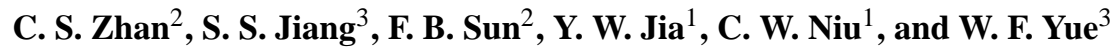 \\ ${ }^{1}$ State Key Laboratory of Simulation and Regulation of Water Cycle in River Basin, China Institute of Water Resources and \\ Hydropower Research, Beijing 100038, China \\ ${ }^{2}$ Key Laboratory of Water Cycle and Related Land Surface Processes, Institute of Geographic Sciences and Natural \\ Resources Research, Chinese Academy of Sciences, Beijing 100101, China \\ ${ }^{3}$ College of Water Sciences, Beijing Normal University, 100875, Beijing, China \\ Correspondence to: S. S. Jiang (jiangshanshan@mail.bnu.edu.cn)
}

Received: 6 January 2014 - Published in Hydrol. Earth Syst. Sci. Discuss.: 17 February 2014

Revised: 2 July 2014 - Accepted: 4 July 2014 - Published: 19 August 2014

\begin{abstract}
Surface runoff from the Wei River basin, the largest tributary of the Yellow River in China, has dramatically decreased over last 51 years from 1958 to 2008. Climate change and human activities have been identified as the two main reasons for the decrease in runoff. The study period is split into two sub-periods (1958-1989 and 1990-2008) using the Mann-Kendall jump test. This study develops an improved climate elasticity method based on the original climate elasticity method, and conducts a quantitative assessment of the impact of climate change and human activities on the runoff decrease in the Wei River basin. The results from the original climate elasticity method show that climatic impacts contribute $37-40 \%$ to the decrease in runoff, while human impacts contribute $60-63 \%$. In contrast, the results from the improved climate elasticity method yield a climatic contribution to runoff decrease of 22-29\% and a human contribution of $71-78 \%$. A discussion of the simulation reliability and uncertainty concludes that the improved climate elasticity method has a better mechanism and can provide more reasonable results.
\end{abstract}

\section{Introduction}

Climate change is expected to extensively alter global hydrological cycles (Legesse et al., 2003; Milly et al., 2005; Piao et al., 2007; Tang et al., 2013) by primarily changing the pattern of precipitation (IPCC, 2013; Sun et al., 2012). After the falling of precipitation into basins, human activities in- cluding land use change, dam construction, river diversion, and other engineering and management practices also modify hydrological cycles locally and therefore temporal and spatial distribution of water resources (Govinda, 1995; Milly et al., 2005). Quantitatively assessing the influence of climate change and human activities on surface runoff is vital for sustainable water resources management.

Quantitative evaluation of the effects of climate change and human activities on runoff has yielded significant results, but with complex regional patterns. For instance, Zhang et al. (2008) used the sensitivity of runoff to precipitation and potential evaporation to study the response of runoff to changes in climate and land use/cover in the Loess Plateau of China and pointed out that LUCC (land use and land cover change) accounted for over $50 \%$ of the reduction in mean annual runoff in 8 out of 11 catchments. Bao et al. (2012) discussed the reasons for runoff changes in the Haihe River basin, analyzed the influence of human activities through the VIC model, and then proved human activities were the main driving force for the reduction of water resources. Wang et al. (2009) established a distributed monthly water balance model (DTVGM) to analyze the Chaobai River basin upstream of Miyun Reservoir in north China, and concluded that human activities were therefore the main cause of runoff changes. Ma et al. (2008) estimated that the effects of climate change accounted for over $64 \%$ of the mean annual runoff reduction in the Shiyang River in the arid region of northwest China. For the same basin, human activities and climate change may have different influences on runoff for 
different periods. For example, Qiu et al. (2012) analyzed the influence of climate change and human activities on water resources in north China and found that in the 1970s-1980s the effects of climate change were dominant, but in the late 1980s and early 1990s the effects of the two factors were similar, and since the 1990s the influence of human activities has been slightly higher at around $55 \%$. Guo et al. (2008) employed the SWAT model to analyze the annual and seasonal runoff variability caused by climate change and human activities and found that the main influencing factor on annual runoff was climate change, but that changing land use was the main influence on seasonal runoff changes.

So far, there are many different methods used to evaluate and separate the effects of the two factors (Sun et al., 2014). One such method is based on physical processes or physical mechanisms. This method controls the evolution of the various elements and analyzes the changes in driving factors and contributions in a physical process simulation. The approach may be physically sound but requires major efforts on model calibration and can lead to remarkably different results because of uncertainty in model structure and parameter estimation (Nash and Gleick, 1991; Revelle and Waggoner, 1983; Schaake, 1990; Vogel et al., 1999). Other methods can be classified as statistical data analysis methods, such as the climate elasticity method used in this paper. The statistical data analysis methods are based on mean annual change trends in long time series, and provide generalized relationships which do not consider species differences. This approach incorporates measured or observed data via a variety of data validation techniques, and analyzes the contributions of different factors on different processes. The method is relatively simple, but requires a large volume of high-quality data (Risbey and Entekhabi, 1996).

Many studies have proven that the climate elasticity method is reasonable and credible (Chen et al., 2014). Chiew (2006) evaluated rainfall elasticity of streamflow in 219 catchments across Australia using the nonparametric climate elasticity estimator and compared the estimates with results obtained from the conceptual rainfall-runoff model SIMHYD, showing a consistent relationship between climate elasticity values estimated using the rainfall-runoff model and the nonparametric estimator. Ma et al. (2010) used a distributed hydrological model (GBHM) and a climate elasticity model to conduct a quantitative assessment of the impacts of climate change and human activities on inflow into a reservoir. The GBHM simulation and climate elasticity model showed that climate change accounts for about 55 and $51 \%$ of the reservoir inflow reduction, respectively. Hu et al. (2012) analyzed the impacts of climate change and human activities on the Baiyangdian upstream runoff, using two assessment methodologies (climate elasticity and hydrological modeling). The climate elasticity method was implemented at the annual scale and was computationally relatively simple; it needed fewer data and parameters to calculate the impacts of climate change on an- nual runoff. The hydrological model was implemented at the daily scale, and therefore needed more data and parameters but yielded more detailed, high temporal resolution results. These two independent methods based on different timescales obtained consistent results. Thus, the climate elasticity method is considered to be an important indicator for quantifying the sensitivity of runoff to climate change and for separating the effects of natural and anthropogenic factors at catchment scale (Dooge et al., 1999; Fu et al., 2007; Milly and Dunne, 2002; Sankarasubramanian et al., 2001; Schaake, 1990; Zheng et al., 2009). However, the main point for the climate elasticity method's previous research indicates is that the method is used to separate the sensitivity of runoff to climate change without considering the human activities directly, and furthermore the accuracy of the original climate elasticity method should be improved.

In this paper we improve the climate elasticity approach by adding the influence of human activities to evaluate the hydrological consequences of climate change and human activities. To compare the original and improved climate elasticity approaches, we choose the Wei River basin as a case study. The application results have a great strategic meaning in the regional economic development and the development of west China (Song et al., 2007). The rest of the paper is structured as follows: Sect. 2 describes the study area and data; Sect. 3 presents the methodology; and results and discussion are in Sect. 4. The conclusions are presented in Sect. 5.

\section{Study area and data}

\subsection{Study area}

The Wei River is the largest tributary in the Yellow River. It originates from Niaoshu Mountain, and runs into the Yellow River at Tongguan. The basin is located between $104^{\circ} 00^{\prime} \mathrm{E}-$ $110^{\circ} 20^{\prime} \mathrm{E}$ and $33^{\circ} 50^{\prime} \mathrm{N}-37^{\circ} 18^{\prime} \mathrm{N}$, with a length of $818 \mathrm{~km}$ and a drainage area of $1.35 \times 10^{5} \mathrm{~km}^{2}$.

The Wei River basin is located in temperate continental monsoon climate region. The climate is cold, dry and rainless in winter controlled by the Mongolia high, while hot and rainy in summer affected by the western Pacific subtropical high. The mean air temperature is 7.8 to $13.5^{\circ} \mathrm{C}$, the mean annual precipitation is 400 to $800 \mathrm{~mm}$, and the mean annual potential evapotranspiration is 800 to $1000 \mathrm{~mm}$. The mean annual runoff in depth is 450 to $550 \mathrm{~mm}$, with the coefficient of variation falling within 0.1 to 0.2 (He et al., 2009).

\subsection{Data description}

This study uses the continuous daily series data from 1958 to 2008 at seven national meteorological observatory stations in and around the Wei River basin. Observed daily mean air temperature, precipitation and solar shortwave radiation could largely reflect climatic change in the region (Fig. 1). In addition, observational runoff data for 1958-2008 comes 


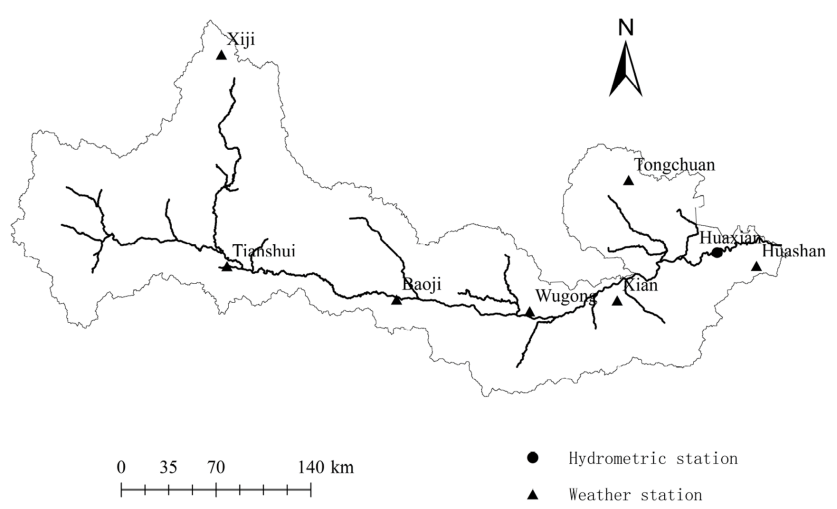

Figure 1. Location of the meteorological and hydrological stations used in this study.

from Hua County hydrological station, located in the river outlet downstream.

The potential evapotranspiration within the watershed can be calculated using the Hargreaves method, an empirical formula which was derived using the permeameter by Hargreaves and Samani (1982) to estimate potential evapotranspiration, and most appropriate in all radiation and temperature estimation methods in north China (Luo and Rong, 2007). The expression is as follows:

$E_{0}=0.0135(T+17.8) \frac{R_{\mathrm{s}}}{\lambda}$,

where $E_{0}$ represents potential evapotranspiration, mm day $^{-1} ; T$ represents mean air temperature, ${ }^{\circ} ; R_{\mathrm{S}}$ represents solar shortwave radiation, $\mathrm{MJ} /\left(\mathrm{m}^{2} \mathrm{day}^{-1}\right) ; \lambda$ represents latency for vaporing water, $\lambda=2.45 \mathrm{MJ} \mathrm{kg}^{-1}$.

\section{Methodology}

\subsection{Detection of hydrologic changes}

\subsubsection{Trend analysis}

In this study, the Mann-Kendall trend test is used to test the long-term trends of precipitation, evaporation and runoff in the Wei River basin. The Mann-Kendall trend test is a nonparametric statistical test method. It does not need the sample to follow any particular distribution, and is not subject to interference from a small number of outliers. Moreover, the method is relatively simple (Mann, 1945; Kendall, 1975).

For a time series $X$ which has $n$ samples, construct variable $S$ :

$S=\sum_{i=1}^{n-1} \sum_{j=i+1}^{n} \operatorname{sgn}\left(x_{i}-x_{j}\right)$,

where $x_{i}$ and $x_{j}$ represent the values in years $i$ and $j, i>$ $j, n$ is the record length of the series, and $\operatorname{sgn}\left(x_{i}-x_{j}\right)$ is a characterization of the function.
The statistical test value $Z_{c}$ is calculated by the following formula:

$Z_{c}= \begin{cases}\frac{S-1}{\sqrt{\operatorname{Var}(S)}}, & S>0 \\ 0, & S=0 \\ \frac{S+1}{\sqrt{\operatorname{Var}(S)}}, & S<0 \\ \cdot & \end{cases}$

When $\left|Z_{c}\right| \leq Z_{1-\alpha / 2}$, we accept the null hypothesis, which indicates the sequence does not have a trend. If $\left|Z_{c}\right|>$ $Z_{1-\alpha / 2}$, we reject the null hypothesis and conclude that the sequence does have a significant trend. $Z_{1-\alpha / 2}$ is obtained from standard normal distribution function, and $\alpha$ is the significance level of the test.

To test the trend of the sequence in the Mann-Kendall test, it is usually necessary to estimate the slope of the monotonic trend, estimated as follows:

$\beta=\operatorname{Media}\left(\frac{x_{i}-x_{j}}{i-j}\right),(\forall j<i, 1 \leq j<i \leq n)$.

A positive value of $\beta$ indicates a rising trend (positive rate of change with time), and vice versa for negative $\beta$.

\subsubsection{Change-point analysis}

Identifying the change-point for runoff substantially influenced by human activities is significant. Depending upon the change-point, the hydrology series could be divided into two periods: before change-point, it was regarded as having no influence from human activities, and after change-point it was believed that human activities sharply affected runoff. Under the hypothesis that the time series is independent and stochastic, we can compute the following statistics:

$\mathrm{UF}_{k}=\frac{S_{k}-E\left(S_{k}\right)}{\sqrt{\operatorname{Var}\left(S_{k}\right)}}(k=1,2, \ldots, n)$,

where $E\left(S_{k}\right)$ and $\operatorname{Var}\left(S_{k}\right)$ represent the mean and variance of $S_{k}$, respectively.

Next, the time series order is reversed (i.e., $x_{n}, x_{n-1}, \ldots$, $x_{1}$ ), and the above process is repeated to yield the statistical variables $\mathrm{UB}_{k}(k=n, n-1, \ldots, 1)$, such that

$\mathrm{UB}_{k}=-\mathrm{UF}_{k}$

Next, the curves of $\mathrm{UB}_{k}$ and $\mathrm{UF}_{k}$ are drawn, and if the two curves have an intersection point and if the value of $U$ at this point satisfies $|U|<1.96$, then that point is regarded as a change point, with a confidence level $\alpha$ of 0.05 . Because the time series length in this study is 51 years, we use a significance test of $t$ test.

\subsection{Original climate elasticity method}

Runoff $(R)$ can be expressed as a function of climate variables $(C)$ and other characteristics $(H)$ (Hu et al., 2012):

$R=f(C, H)$, 
where the parameter $H$ represents the combined results of terrain, soil, land use/land cover and human activities (such as artificial water transfer). If the topography and soil in the study area remain constant during the study period, then $H$ can represent human activities. So the runoff change can be expressed as

$\Delta R=\Delta R_{\mathrm{C}}+\Delta R_{\mathrm{H}}$,

where the parameter $\Delta R$ represents the total runoff change; and $\Delta R_{\mathrm{C}}, \Delta R_{\mathrm{H}}$ represent the runoff changes caused by climate change and human activities, respectively.

The total runoff change can be obtained from the formula $\Delta R=R_{\mathrm{obs} 1}-R_{\mathrm{obs} 2}$, where $R_{\mathrm{obs} 1}$ and $R_{\mathrm{obs} 2}$ represent the measured runoff before and after the change point, respectively.

Schaake (1990) first introduced the climate elasticity method to analyze the sensitivity of runoff to climate change. Climate elasticity of runoff $\left(\varepsilon_{X}\right)$ can be defined as the proportional change in runoff $(R)$ relative to the change in climatic variables $(X)$ (such as changes in precipitation or potential evapotranspiration) (Fu et al., 2007):

$\varepsilon_{X}=\frac{\partial R / R}{\partial X / X}$.

According to the long-term water balance equation $(R=$ $P-E$ ), we assume that the runoff response to climate factors is mainly caused by the precipitation and potential evapotranspiration. According to the theory of total differential equations, the differential form is as follows:

$\Delta R_{\mathrm{C}}=\varepsilon_{P} \frac{R}{P} \Delta P+\varepsilon_{E_{0}} \frac{R}{E_{0}} \Delta E_{0}$ and $\varepsilon_{P}+\varepsilon_{E_{0}}=1$,

where $\Delta R_{\mathrm{c}}$ represents runoff change caused by climate change, $\Delta P$ and $\Delta E_{0}$ are the change of precipitation and potential evapotranspiration, and $\varepsilon_{P}$ and $\varepsilon_{E_{0}}$ are the precipitation and potential evapotranspiration elasticities of runoff, respectively.

According to the Budyko hypothesis, actual evapotranspiration $(E)$ is a function of the dryness indices $\left(\phi=E_{0} / P\right)$, specifically $E=P * F(\phi)$, and the precipitation and potential evapotranspiration elasticities of stream flow can be expressed as

$\varepsilon_{P}=1+\phi F^{\prime}(\phi) /(1-F(\phi)) \varepsilon_{E_{0}}=-\phi F^{\prime}(\phi) /(1-F(\phi))$.

The following formulae (one with a parameter and the others without) for the Budyko hypothesis are often used to estimate $F(\phi)$, as shown in Table 1 .

According to Table 1 , the precipitation elasticity $\left(\varepsilon_{p}\right)$ and potential evapotranspiration elasticity $\left(\varepsilon_{E_{0}}\right)$ can be determined, allowing the runoff change caused by climate change $\left(\Delta R_{\mathrm{c}}\right)$ to be calculated, and thus the contribution of climate change can be assessed. Calibration of Zhang's (2001) formula using land cover and land use conditions yielded a parameter value of 1.5 .

\subsection{Improved climate elasticity method}

At the catchment scale, and over a long time period, the water balance equation can be simplified as $P=E+R$. Here the mean annual runoff $R$ can be divided into observed runoff and changing runoff caused by human activities, i.e., $R=R_{\text {obs }}+R_{\mathrm{H}}$, where $R_{\text {obs }}$ is observed runoff. $R_{\mathrm{H}}$ refers mainly to water consumption or water intake by human activities which mainly include measures of water and soil conservation, river dam construction, water intake from rivers, water transfer and so on. So the water balance equation can be expressed as $P=R_{\mathrm{obs}}+R_{\mathrm{H}}+E$, which in differential form is

$\mathrm{d} P=\mathrm{d} R_{\text {obs }}+\mathrm{d} R_{\mathrm{H}}+\mathrm{d} E$.

Meanwhile, according to the Budyko hypothesis $E=$ $P F(\phi), \phi=E_{0} / P$, the total differential form can be expressed as

$\mathrm{d} E=\left[F(\phi)-\phi F^{\prime}(\phi)\right] \mathrm{d} P+F^{\prime}(\phi) \mathrm{d} E_{0}$.

When substituted into Eq. (12), this leads to

$\mathrm{d} R_{\mathrm{obs}}=\left[1-F(\phi)+\phi F^{\prime}(\phi)\right] \mathrm{d} P-F^{\prime}(\phi) \mathrm{d} E_{0}-\mathrm{d} R_{\mathrm{H}}$.

After dividing Eq. (14) by $R_{\mathrm{obs}}$, we obtain the following equation:

$$
\begin{aligned}
\frac{\mathrm{d} R_{\mathrm{obs}}}{R_{\mathrm{obs}}} & =\left[1-F(\phi)+\phi F^{\prime}(\phi)\right] \frac{P}{R_{\mathrm{obs}}} \frac{\mathrm{d} P}{P} \\
& -F^{\prime}(\phi) \frac{E_{0}}{R_{\mathrm{obs}}} \frac{\mathrm{d} E_{0}}{E_{0}}-\frac{R_{\mathrm{H}}}{R_{\mathrm{obs}}} \frac{\mathrm{d} R_{\mathrm{H}}}{R_{\mathrm{H}}} .
\end{aligned}
$$

The climate and anthropic elasticities are calculated as follows:

$\varepsilon_{P}=\left[1-F(\phi)+\phi F^{\prime}(\phi)\right] \frac{P}{R_{\mathrm{obs}}}$

$\varepsilon_{E_{0}}=-F^{\prime}(\phi) \frac{E_{0}}{R_{\mathrm{obs}}}$

$\varepsilon_{\mathrm{H}}=-\frac{R_{\mathrm{H}}}{R_{\mathrm{obs}}}$,

which satisfy $\varepsilon_{P}+\varepsilon_{E_{0}}+\varepsilon_{\mathrm{H}}=1$.

From Table 1 and Eq. (16), the elastic coefficients $\varepsilon_{P}, \varepsilon_{E_{0}}$, and $\varepsilon_{\mathrm{H}}$, which respectively represent the precipitation, evapotranspiration, and human activities elasticities, can be calculated. Next, the runoff change $R_{\mathrm{H}}$ caused by human activities is computed. The contribution of human activities to runoff can be expressed by $P_{\mathrm{H}}$, where $P_{\mathrm{H}}=R_{\mathrm{H}} / \Delta R$, thus the contribution of climate change can also be calculated.

\section{Results and discussion}

\subsection{Detection of hydrologic changes}

In this study, the Mann-Kendall trend test is adopted to determine the significance of the trends in runoff, precipitation 
Table 1. Different formulae for the Budyko hypothesis.

\begin{tabular}{lll}
\hline Expression & $F(\phi)$ & $F^{\prime}(\phi)$ \\
\hline Turc (1954); Pike (1964) & $\left(1+\phi^{-2}\right)^{-0.5}$ & $1 /\left[\phi^{3}\left(1+(1 / \phi)^{2}\right)^{1.5}\right]$ \\
\hline Zhang (2001) & $(1+w \phi) /(1+w \phi+1 / \phi)$ & $\left(w+2 w / \phi-1+1 / \phi^{2}\right) /(1+w \phi+1 / \phi)^{2}$ \\
\hline
\end{tabular}

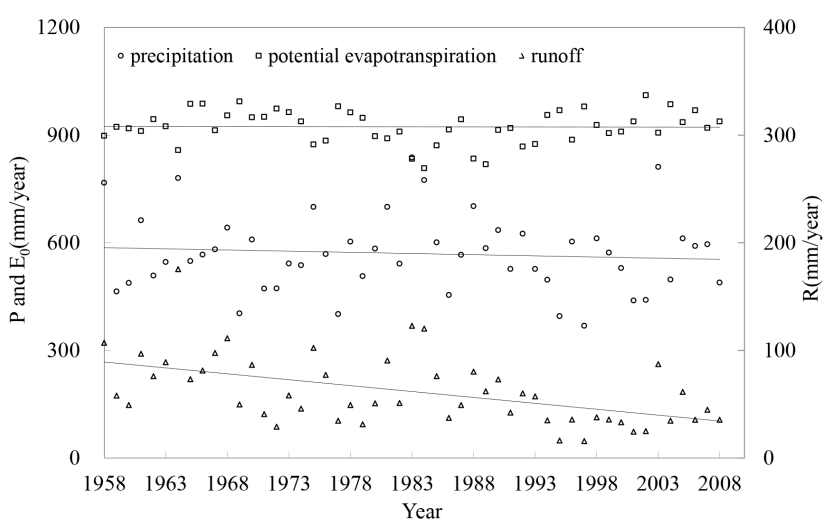

Figure 2. Time series of annual precipitation, annual potential evapotranspiration and annual runoff in the Wei River basin from 1958 to 2008 .

and potential evapotranspiration, and to analyze the trends in meteorological factors and corresponding runoff changes over nearly 50 years. Figure 2 shows time series of precipitation, potential evapotranspiration and runoff from 1958 to 2008, and the runoff series are observed at the hydrological gauging station located the river basin outlet. Qualitative inspection shows that the trends in precipitation and potential evapotranspiration are not obvious, while runoff notably decreases. The fluctuation range of potential evapotranspiration is not obvious in different years, but the fluctuation range of precipitation is significant, and its overall trends are stable. Thus, the decrease of runoff implies that precipitation and potential evapotranspiration are not the only influencing factors on runoff, and instead human activities may have been the main influence on the decreasing runoff.

The Mann-Kendall test is also used to analyze the change point of the runoff in the Wei River basin, at a confidence level set to $\alpha=0.05$. The normal distribution shows that the critical value was $U_{\alpha / 2}=1.96$. The result of the changepoint test is presented in Fig. 3. It can be seen in Fig. 3 that the two curves intersect in 1990, and the intersection is within the critical value range $U_{\alpha / 2}= \pm 1.96$. The result illustrates that an abrupt change of runoff occurred in 1990.

According to the results of trend analysis and change-point analysis, the monthly runoff data in the periods of 19581990 and 1990-2008 is used to plot the flow duration curve (FDC) that indicates the runoff change of the basin in different periods, and the monthly runoff series are observed at

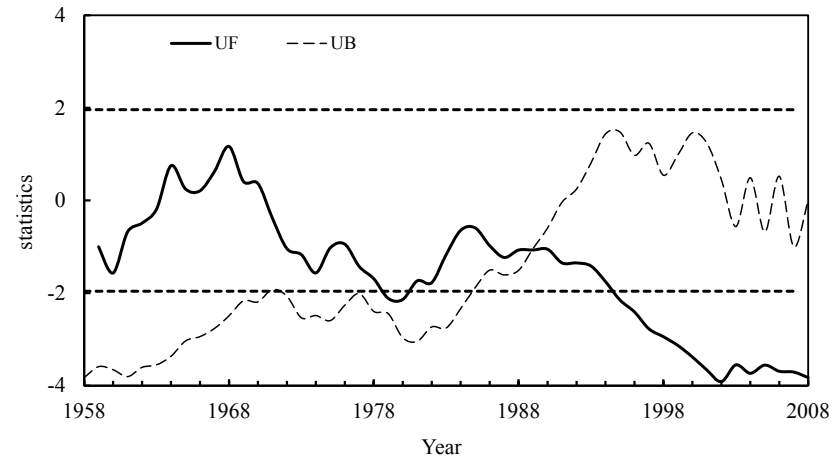

Figure 3. The result of the abrupt change-point test in the Wei River basin.

the hydrological gauging station located the river basin outlet. Vogel and Fennessey (1994) provide the details of the FDC method, which represents the relationship between the magnitude and frequency of runoff, and provides an estimate of the percentage of time a given runoff that is equal to or exceeds an historical period. The relationship between the magnitude and frequency of monthly average runoff are shown in Fig. 4, which indicates that the percentage of time runoff exceeded in the period 1958-1990 is larger than that for 1990-2008, and the runoff relative change for the two periods only have large fluctuations at percentages less than $10 \%$ and more than $90 \%$. Figure 4 also implies the decrease of runoff for 1990-2008 correlates with human activities. Furthermore, the influence on decreasing runoff is facilitated by the high-flow and low-flow periods at which the percentage time runoff exceeded is less than $10 \%$ and more than $90 \%$.

\subsection{Results of the original and improved climate elasticity methods}

\subsubsection{Original climate elasticity method}

In order to evaluate the influence on runoff caused by climate change, Eq. (11) is first used to calculate the elasticities of precipitation and potential evapotranspiration for 1958 2008, which can be expressed as $\varepsilon_{P}$ and $\varepsilon_{E_{0}}$, respectively, as shown in Table 2 . These results reveal that if precipitation decreases by $10 \%$, runoff will decrease by $25.8-27.7 \%$, and if potential evapotranspiration decreases by $10 \%$, runoff will 


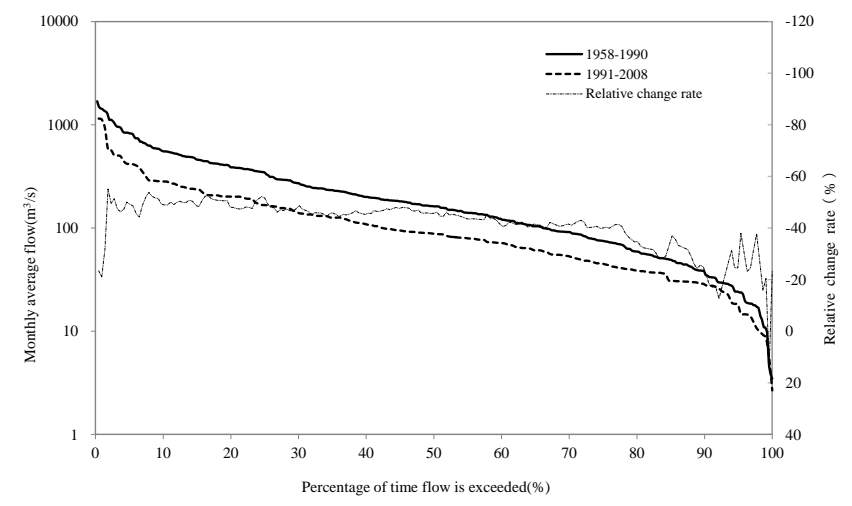

Figure 4. Flow duration curves under different periods in the Wei River basin.

increase by $15.8-17.7 \%$. Then, according to the calculated $\varepsilon_{P}, \varepsilon_{E_{0}}$ and Eq. (10), the runoff decrease caused by climate change can be computed. The total contribution of precipitation and potential evapotranspiration to the runoff decrease is $32.1 \mathrm{~mm}$. Therefore, the contribution of climate change to the runoff decrease is $37-40 \%$, and the contribution of human activities is $60-63 \%$.

\subsubsection{Improved climate elasticity method}

In order to evaluate the influence on runoff caused by human activities, Eq. (16) is first used to calculate the elasticities of precipitation, potential evapotranspiration and human activities for 1958-2008, which can be expressed as $\varepsilon_{P}, \varepsilon_{E_{0}}$ and $\varepsilon_{\mathrm{H}}$, respectively, as shown in Table 3 . We realize that if annual runoff decreases by $32.1 \mathrm{~mm}$, the decrease caused by human activities is $22.9-24.9 \mathrm{~mm}$. So the contribution of human activities to runoff decrease is $71-78 \%$, and the contribution of climate change is $22-29 \%$.

\subsubsection{Comparison of the simulation results}

In this paper, two methods are used to analyze the causes of the runoff decrease in the Wei River basin. One is the original climate elasticity method, and the other is the improved climate elasticity method. Each method adopts two formulas based on the Budyko hypothesis (noting that one formula includes parameters and the other does not). Results are compared with each other and with those calculated by other methods, and the precision of the two methods is analyzed. Both methods are implemented at the annual timescale, and require relatively simple computation. The contributions of climate change and human activities to runoff variability can thus be computed by fewer data and parameters compared with other methods. The results of the original climate elasticity method show that the contributions of climate change and human activities to runoff variability are 37-40\% and $60-63 \%$, respectively. Meanwhile, corresponding contributions calculated using the improved climate elasticity method are $22-29 \%$ and $71-78 \%$, respectively. Early studies showed that during the 1970-1995 period, the contribution of human activities to runoff decrease was $58.3 \%$ in the Wei River basin (Zhang and Wang, 2007). In recent years, human activities have intensified, so that by 2008 the contribution of human activities most likely increased, and may now exceed $60 \%$. Gao et al. (2013) found that the contribution of human activities to reduced stream flow in the Wei River basin was even as high as $82.80 \%$. Zhan et al. (2014) used the SIMHYD model to partition the effects of climate change and human activities on surface runoff in the Wei River basin and found that the contribution rate of human activities to stream flow change was more than $65 \%$. The results of the improved climate elasticity method are closer to the existing results than those of the original, suggesting that the improved climate elasticity method, which is more adaptable and easier to implement, is much more reliable and practical.

Moreover, it is important to note that the improved climate elasticity method is the first to introduce human activities' elasticity $\varepsilon_{\mathrm{H}}$. Without the trend analysis and changepoint test, the strength of the influence of human activities on runoff changes can be calculated. When calculating the contribution of human activities to runoff changes, the changepoint test is needed so that the total runoff decrease can be calculated.

The improved climate elasticity method broadens the concept of climate elasticity, and provides a more intuitive and practical formula for calculating the contribution of human activities to runoff changes. Compared with the hydrological simulation method, the climate elasticity method not only needs fewer data and parameters, and is more reliable and easier to implement, but can also be easily extended. However, its temporal resolution is low and it lacks a physical basis. There is a trend towards coupling hydrological simulations with the more reliable hydrological and meteorological statistical methods, to quantitatively study hydrological responses to climate change and human activities.

\subsection{Discussion}

In this paper it is assumed that over a long period of time, change in catchment storage can be neglected, so that the water balance equation can be expressed as $P=E+R$. It is also assumed that the Budyko curve can comparably and precisely estimate mean annual evaporation. In fact the two assumptions are fundamental and commonly used in Budykotype elasticity studies for long-term averages (Gentine et al., 2012). We do not think there is an approach that can estimate the mean annual evaporation "precisely" but if any, the Budyko curve would be comparable at least for long-term means.

The maximum daily precipitation as well as the averaged top five maximum daily precipitation for each year are estimated as shown in Fig. 5. The results show that there is no steady decreasing trend in these two measures of extreme 
Table 2. Results of the original climate elasticity method.

\begin{tabular}{clccccccc}
\hline Period & Formula & $P / \mathrm{mm}$ & $E_{0} / \mathrm{mm}$ & $\varepsilon_{P}$ & $\varepsilon_{E_{0}}$ & $\Delta R_{\mathrm{C}} / \mathrm{mm}$ & $\Delta R_{\mathrm{C}} / \%$ & $\Delta R_{\mathrm{H}} / \%$ \\
\hline \multirow{2}{1958-2008}{} & Turc (1954); Pike (1964) & 569.3 & 923.1 & 2.77 & -1.77 & 11.9 & 37 & 63 \\
$1958-2008$ & Zhang (2001) & 569.3 & 923.1 & 2.58 & -1.58 & 12.9 & 40 & 60 \\
\hline
\end{tabular}

Table 3. Results of the improved climate elasticity method.

\begin{tabular}{clrrrrrrrr}
\hline \multicolumn{1}{c}{ Period } & Formula & $P / \mathrm{mm}$ & $E_{0} / \mathrm{mm}$ & $\varepsilon_{p}$ & $\varepsilon_{E_{0}}$ & $\varepsilon_{\mathrm{H}}$ & $\Delta R_{\mathrm{H}} / \mathrm{mm}$ & $\Delta R_{\mathrm{C}} / \%$ & $\Delta R_{\mathrm{H}} / \%$ \\
\hline 1958-2008 & Turc (1954); Pike (1964) & 569.3 & 923.1 & 3.53 & -2.16 & -0.37 & 22.9 & 29 & 71 \\
$1958-2008$ & Zhang (2001) & 569.3 & 923.1 & 3.89 & -2.49 & -0.40 & 24.9 & 22 & 78
\end{tabular}

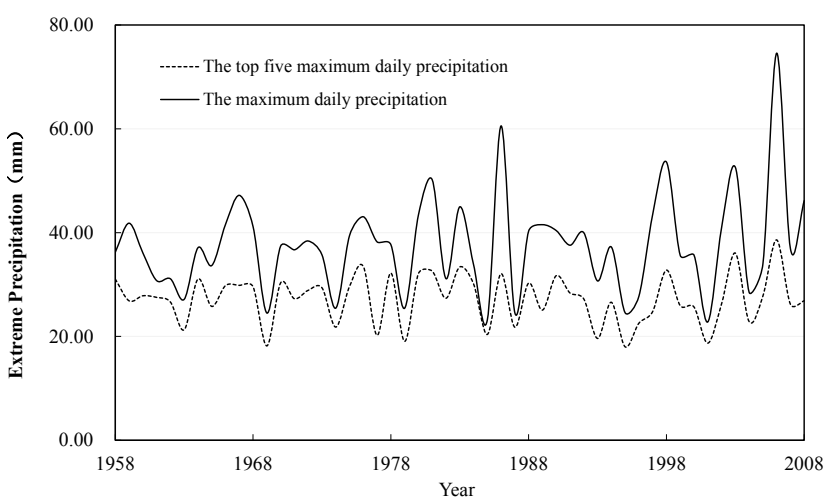

Figure 5. The top five maximum daily precipitation and the maximum daily precipitation curves.

rainfall and distribution, while the steady decrease in runoff investigated in this study would require a steady decrease in rainfall intensity if the change in distribution is the cause. Those results are consistent with our experience with this catchment in that precipitation and potential evapotranspiration are not the only influencing factors on runoff, but instead human activities have been the main influence on the decreasing runoff.

The impacts of human activities on runoff are reflected in land use and land cover changes. Land use and land cover change is a gradual process, and the impacts on runoff also accumulate gradually. We can decrease the uncertainty of quantitative predictions by analyzing the LUCC changes in the Wei River basin in 1980, 1990, 2000, 2005 and 2007, and then checking whether the results are reasonable. The main type of land cover in the Wei River basin is cultivated land, which covers more than $50 \%$ of the total area, followed by woodland and grassland.

By analyzing the changing areas of cultivated land and woodland and grassland in the Wei River basin in 1980, 1990, 2000, 2005 and 2007, it can be concluded that the year 1990 is the turning point in cultivated land area, since the area decreases during the 1980-1990 period, and then begins to increase again after 1990. The year 1990 is also the turn- ing point in the area of woodland and grassland area, but the corresponding trends are opposite to those of the cultivated area. Because the area of cultivated land and woodland and grassland reaches $90 \%$, and considering the turning points of the three types of land, the year 1990 can be regarded as a more general turning point in surface characteristics (Song et al., 2012). This decreases the uncertainty regarding 1990 as the runoff change point.

Major sources of uncertainty in the simulation associated with the climate elasticity may arise from the input data, classification of the stages, and the parameter in the Zhang (2001) formula. Precipitation data used in the models are from seven rain gauges and meteorological stations in and around the study catchment. The flow data are measured during the 1958-2008 period from the Hua County hydrological station, which is located at the downstream end of the basin, but may not sufficiently represent the whole basin. Even though the breakpoint test is found to be reasonable, there remain some uncertainties, which may be caused by the test method and artifacts when reading the results in the chart. The parameter which is very sensitive in the Zhang (2001) formula is calibrated according to the land cover and land use conditions.

Furthermore, it is essential to point out that climate change and human activities are supposed to be two mutually independent variables when separating their impacts on runoff; however, we note that land use and land cover can be influenced by both climate change and by human activities.

In this study $R$ is divided into $R_{\mathrm{obs}}$ and $R_{\mathrm{H}}$ because the water intake directly from rivers is a significant amount in almost all rivers in China. However, in the original Budykotype elasticity, this part is not considered directly and the main formulae are $\Delta R=\varepsilon_{P} \frac{\mathrm{d}_{P}}{P}+\varepsilon_{E_{0}} \frac{\mathrm{d}_{E_{0}}}{E_{0}}$ and $\Delta R=\Delta R_{\mathrm{C}}+$ $\Delta R_{\mathrm{H}}$. Then that framework is extended by including the direct influence from water intake to adapt to catchments with intense water consumption and intake, and the main formula is $\Delta R=\varepsilon_{P} \frac{\mathrm{d}_{P}}{P}+\varepsilon_{E_{0}} \frac{\mathrm{d}_{E_{0}}}{E_{0}}+\varepsilon_{\mathrm{H}} \frac{\mathrm{d}_{R_{\mathrm{H}}}}{R_{\mathrm{H}}}$. We believe this is a new contribution to the climate elasticity method reported in literatures. 


\section{Conclusions}

Decreasing runoff in many rivers in China has been reported in recent years, and the Wei River basin is one of the most serious cases. This paper aims at developing a new approach to quantifying the impact of climate variations and human activities on this decreasing runoff in the Wei River basin. The man-made changes here include land use, vegetation, and other land surface conditions, while climate change and climate variability are reflected in precipitation and potential evapotranspiration. This study uses the Mann-Kendall test to assess the temporal trends in precipitation, potential evapotranspiration and runoff, and also analyzes the point of abrupt change. On this basis, the original climate elasticity method and improved climate elasticity method are used to analyze the quantitative hydrological effects of climate change and human activities; these findings are then compared to existing results from the hydrological simulation method. This study shows the following:

In the last 50 years, the runoff from the Wei River basin has obviously decreased, but the precipitation and potential evapotranspiration have shown no clear trend. Therefore it can be seen that climate factors have not obviously contributed to the runoff decrease.

From 1958 to 2008, the runoff in the Wei River basin shows an abrupt change in 1990, effectively dividing the total runoff into natural runoff processes and runoff processes affected by human activities. At the same time, this change shows that human activities have significant effects on runoff.

Human activities resulted in a shift in land use and land cover in 1990, and the type of land use and land cover has a great influence on runoff. This illustrates that human activities, especially those causing land use and land cover change, are the main reason for the runoff decrease.

The original climate elasticity method shows that the contributions of climate change and human activities to runoff decrease are $37-40 \%$ and $60-63 \%$, respectively, but the improved climate elasticity method indicated that the contributions of climate change and human activities to runoff decrease are $22-29 \%$ and $71-78 \%$, respectively. The result of the improved climate elasticity method is closer to those results based on comprehensive hydrological models, thereby demonstrating that human activities are the main reason for the runoff decrease in the Wei River basin.

Acknowledgements. This work was partially supported by the National Natural Science Foundation of China (41271003, 41371043, 50939006), Key Project for the Strategic Science Plan in IGSNRR, Chinese Academy of Sciences (2012ZD003), and the Open Research Fund of State Key Laboratory of Simulation and Regulation of Water Cycle in River Basin (China Institute of Water Resources and Hydropower Research) (IWHR-SKL-201311).

\section{References}

Bao, Z. X., Zhang, J. Y., Wang, G. Q., Fu, G. B., He, R. M., Yan, X. L., Jin, J. L., Liu, Y. L., and Zhang, A. J.: Attribution for decreasing runoff of the Haihe River baisn, northern China: Climate variability or human activities?, J. Hydrol., 460-461, 117-129, 2012.

Chen, J. X., Xia, J., Zhao, C. S., Zhang, S. F., Fu, G. B., and Ning, L. K.: The mechanism and scenarios of how mean annual runoff varies with climate change in Asian monsoon areas, J. Hydrol., 517, 595-606, doi:10.1016/j.jhydrol.2014.05.075, 2014

Chiew, F. H. S.: Estimation of rainfall elasticity of streamflow in Australia, Hydrol. Sci. J., 51, 613-625, 2006.

Dooge, J. C. I., Bruen, M., and Parmentier, B.: A simple model for estimating the sensitivity of runoff to long-term changes in precipitation without a change in vegetation, Adv. Water Resour., 23, 153-163, 1999.

Fu, G., Charles S. P., and Chiew, F. H. S.: A two-parameter climate elasticity of runoff index to assess climate change effects on annual runoff, Water Resour. Res., 43, W11419, doi:10.1029/2007WR005890, 2007.

Gao, P., Geissen, V., Ritsema, C. J., Mu, X.-M., and Wang, F.: Impact of climate change and anthropogenic activities on stream flow and sediment discharge in the Wei River basin, China, Hydrol. Earth Syst. Sci., 17, 961-972, doi:10.5194/hess-17-9612013, 2013.

Gentine, P., D’Odorico, P., Lintner, B. R., Sivandran, G., and Salvucci, G.: Interdependence of climate, soil, and vegetation as constrained by the Budyko curve, Geophys. Res. Lett., 39, L19404, doi:10.1029/2012GL053492, 2012.

Govinda, R. P.: Effect of climate change on stream flows in the Mahanadi river basin, India, Water Int., 20, 205-212, 1995.

Guo, H., Hu, Q., and Jiang, T.: Annual and seasonal runoff responses to climate and land-cover changes in the Poyang Lake basin, China, J. Hydrol., 355, 106-122, 2008.

Hargreaves, G. H. and Samani, Z. A.: Estimating of potential evapotranspiration, J. Irrig. Drain. Divdide, Proceedings of the American Society of Civil Engineers, 108, 223-230, 1982.

He, H. M., Zhang, Q. F., Zhou, J., Fei, J., and Xie, X. P.: Coupling climate change with hydrological dynamic in Qinling Mountains, China, Clim. Change, 94, 409-427, 2009.

Hu, S. S., Zheng, H. X., Liu, C. M., Yu, J. J., and Wang, Z. G.: Assessing the Impacts of Climate Variability and Human Activities on Streamflow in the Water Source Area of Baiyangdian Lake, Acta Geogr. Sinica, 67, 62-70, 2012.

IPCC: Climate Change 2013: The Physical Science Basis, available at: http://www.buildingclimatesolutions.org/view/article/ 524b2c2f0cf264abcd86106a (last access: 20 December 2013), 2013.

Kendall, M. G.: Rank Correlation Measures, Charles Griffin, London, 1975.

Legesse, D., Vallet-Coulomb, C., and Gasse, F.:Hydrological response of a catchment to climate and land use changes in Tropical Africa: case study South Central Ethiopia, J. Hydrol., 275, 67-85, 2003.

Luo, J. and Rong, Y. S.: Evaluation on several Empirical methods for estimating potential evapotranspiration in North China[OL], 2007 (in Chinese). 
Ma, H., Yang, D. W., Tan, S. K., Gao, B., and Hu, Q. F. :Impact of climate variability and human activity on streamflow decrease in Miyun Reservoir catchment, J. Hydrol., 389, 317-324, 2010.

Ma, Z. M., Kang, S. Z., Zhang, L., Tong, L., and Su, X. L.: Analysis of impacts of climate change and human activity on runoff for a river basin in arid region of northwest China, J. Hydrol., 352, 239-249, 2008.

Mann, H. B.: Nonparametric tests against trend. Econometrica, J. Econometric Soc., 13, 245-259, 1945.

Milly, P. C. D. and Dunne, K. A.: Macro-scale water fluxes 2. Water and energy supply control of their inter-annual variability, Water Resour. Res., 38, 241-249, doi:10.1029/2001WR000760, 2002.

Milly, P. C. D., Dunne, K. A., and Vecchia, A. V.: Global pattern of trends in runoff and water availability in a changing climate, Nature, 438, 347-350, 2005.

Nash, L. L. and Gleick, P. H.: Sensitivity of streamflow in the Colorado basin to climatic changes, J. Hydrol., 125, 221-241, doi:10.1016/0022-1694(91)90030-L, 1991.

Piao, S. L., Friedlingstein, P., Ciais, P., de Noblet-Ducoudre, N., Labat, D., and Zaehle, S.: Changes in climate and land use have a larger direct impact than rising $\mathrm{CO}_{2}$ on global river runoff trends, Proc. Natl. Acad. Sci, 104, 15242-15247, 2007.

Pike, J. G.: The estimation of annual run-off from meteorological data in a tropical climate, J. Hydrol., 2, 116-123, 1964.

Qiu, G. Y., Yin, J., and Shu, G.: Impact of climate and land-use changes on water security for agriculture in Northern China, J. Integrat. Agr., 11, 144-150, 2012.

Revelle, R. R. and Waggoner, P. E.: Effects of a carbon dioxideinduced climatic change on water supplies in the western United States, in: Changing Climate, 419-432, Natl. Acad., Washington, D.C., 1983.

Risbey, J. S. and Entekhabi, D.: Observed Sacramento basin streamflow response to precipitation and temperature changes and its relevance to climate impact studies, J. Hydrol., 184, 209-223, doi:10.1016/0022-1694(95)02984-2, 1996.

Sankarasubramanian, A., Vogel, R. M., and Limbrunner, J. F.: Climate elasticity of runoff in the United States, Water Resour. Res., 37, 1771-1781, doi:10.1029/2000WR900330, 2001.

Schaake, J. C. and Waggoner, P. E.: From climate to flow, Climate change and US water resources, 177-206, 1990.

Song, J. X., Xu, Z. X., Liu, C. M., and Li, H. E.: Ecological and environmental instream flow requirements for the Wei River the largest tributary of the Yellow River, Hydrol. Process., 21, 1066-1073, 2007.

Song, W. N., Zhan, C. S., Li, J. Y., Xu, Z. X., and Wang, H. X.: Remote Sensing Analysis on the Spatial-temporal Characteristics of LUCC in the Guanzhong Plain Region of the Wei River Basin in the Past 30 years, China Land Sci., 2, 56-62, 2012 (in Chinese).
Sun, F., Roderick, M. L., and Farquhar, G. D.: Changes in the variability of global land precipitation, Geophys, Res. Lett., 39, L19402, doi:10.1029/2012GL053369, 2012.

Sun, Y., Tian, F. Q., Hu, H. P., and Yang, L.: Attributing streamflow decrease to variations in climate conditions and catchment properties across the Upper Han River basin, China, J. Hydrol., 508, 170-180, 2014.

Tang, Y., Tang, Q., Tian, F., Zhang, Z., and Liu, G.: Responses of natural runoff to recent climatic variations in the Yellow River basin, China, Hydrol. Earth Syst. Sci., 17, 4471-4480, doi:10.5194/hess-17-4471-2013, 2013.

Turc, L.: Le bilan d'eau des sols. Relations entre les precipitations,l'evaporation et l'ecoulement, Ann. Agronomy, 5, 491596, 1954.

Vogel, R. M. and Fennessey, N. M.: Flow-duration curves. I: New interpretation and confidences intervals, J. Water Resour. Plann. Manage., 120, 485-504, 1994.

Vogel, R. M., Wilson, I., and Daly, C.: Regional regression models of annual streamflow for the United States, J. Irrig. Drain. Eng., 125, 148-157, doi:10.1061/(ASCE)07339437(1999)125:3(148), 1999.

Wang, G. S., Xia, J., and Chen, J.: Quantification of effects of climate variations and human activities on runoff by a monthly water balance model: a case study of the Chaobai River basin in northern China, Water Resour. Res., 45, W00A11, doi:10.1029/2007WR006768, 2009.

Zhan, C., Zeng, S., Jiang, S., Wang, H., and Ye, W.: An Integrated Approach for Partitioning the Effect of Climate Change and $\mathrm{Hu}-$ man Activities on Surface Runoff, Water Resour. Manage., 28, 3843-3858, 2014.

Zhang, J. Y. and Wang, G. Q.: Research on climate change impact on hydrology and water resources[M], 2007 (in Chinese).

Zhang, L., Dawes, W. R., and Walker, G. R.: Response of mean annual evapotranspiration to vegetation changes at catchment scale, Water Resour. Res. 37, 701-708, 2001.

Zhang, X. P., Zhang, L., Zhao, J., Rustomji, P., and Hairsine, P.: Response of streamflow to changes in climate and land use/cover in the Loess Plateau, China, Water Resour. Res., 44, W00A07, doi:10.1029/2007WR006711, 2008.

Zheng, H., Zhang, L., Zhu, R., Liu, C., Sato, Y., and Fukushima, Y.: Responses of runoff to climate and land surface change in the headwaters of the Yellow River Basin, Water Resour. Res., 45, W00A19, doi:10.1029/2007WR006665, 2009. 